\title{
Research on the Current situation and Countermeasures of Taekwondo Team in Jiangxi Province
}

\author{
Kongmei Dong \\ Military Department of Jiangxi Agricultural University, Nanchang, Jiangxi Province, China \\ 834764288@qq.com
}

Keywords: Taekwondo; Jiangxi Province; Taekwondo team of Jiangxi Province; Countermeasures

\begin{abstract}
Taekwondo team in Jiangxi Province is a competent team and has won many excellent records. Based on the collection of massive literatures and long-term field investigation, the author of this paper constantly studies and compares the advancement and deficiencies of the current development of the Taekwondo teams in many provinces and summarizes their experiences, based on which a series of deep analyses are carried out on the development and current situation of the Taekwondo team in Jiangxi Province. Then, the author puts forward the viewpoints and solutions according to the characteristics of Taekwondo, to obtain corresponding countermeasures to enhance the overall strength of the Taekwondo team of Jiangxi Province and even make some contributions to Taekwondo career of Jiangxi Province even the country.
\end{abstract}

\section{Introduction}

As a competitive sport, Taekwondo is rapidly developing in the world and it was established as the official Olympic Games event in 2000. Olympic glory plan issued by Chinese State Sports General Administration made it clear that: Taekwondo is an important competition item. At Sydney Olympics, Chen Zhong, a Chinese athlete above $67 \mathrm{~kg}$, won the first Olympic gold medal in China's Taekwondo program. [1] To date, athletes of Taekwondo in China have obtained good results of dozens of medals in several major international competitions, including individual gold medals of World Championships and World Cup. [1] At this moment, the competitive level of Taekwondo in our country has been hitherto unknown and has grown rapidly with undeniable momentum. Under such environment, there have been waves of learning and practicing Taekwondo all over the country, and sports groups at all levels in provinces and municipalities have also vigorously developed.

\section{The Development of Taekwondo in Jiangxi Province}

Coach Team. At present, there is only Wang Ting who acts as the coach in Taekwondo team of Jiangxi Province. Wang Ting graduated from sports training professional of Beijing Sport University and became a coach after ten-year of athlete life. She has a wealth of practical experience and expertise skills, as well as a wealth of training experience. She is strict and very patient in everyday training. In recent years, the development of Taekwondo in Jiangxi Province is very rapid, many colleges and universities have set up their own Taekwondo teams, such as Jiangxi Normal University, Nanchang University and Jiangxi Jiaotong University, which also participate in the National Taekwondo competitions. There are professional courses of Sport College of Jiangxi Normal University. A few students who retire from the provincial team usually participate in Taekwondo competitions in colleges and universities on behalf of Jiangxi Normal University.

Athlete Team. At present, there are 22 athletes in Jiangxi Taekwondo team, The best athletes in the province are selected through provincial competitions. The combined teams naturally represent the highest level in the province, and then after a series of more formal and rigorous trainings, they represent Jiangxi Province in the national competitions. 
Table 1 Statistics of Taekwondo Athletes in Jiangxi Province

\begin{tabular}{|c|c|c|c|c|}
\hline $\begin{array}{c}\text { Gen } \\
\text { der }\end{array}$ & $\begin{array}{c}\text { Nu } \\
\text { mbe } \\
\mathrm{r}\end{array}$ & $\begin{array}{c}\text { Number of participants in } \\
\text { provincial competitions }\end{array}$ & $\begin{array}{c}\text { Number of people eligible for } \\
\text { national championships }\end{array}$ & $\begin{array}{c}\text { Number of } \\
\text { participants of } \\
\text { national games }\end{array}$ \\
\hline $\begin{array}{c}\text { Mal } \\
\mathrm{e}\end{array}$ & 8 & 8 & 8 & 4 \\
\hline $\begin{array}{c}\mathrm{Fe} \\
\mathrm{mal} \\
\mathrm{e}\end{array}$ & 14 & 14 & 8 & 4 \\
\hline $\begin{array}{c}\text { Tot } \\
\text { al }\end{array}$ & 22 & 22 & 16 & 8 \\
\hline
\end{tabular}

Competition Results. In the past few years under the leadership of hard-working coach Wang, the performance is quite satisfactory. In the last three years, there are three athletes who won the first three prizes of the national championships, two champions for the youth competition, four third prizes and the total score of women's team listed at the first. There are two first prizes and one third prize of the first Youth Games of 2015.In the National Games of 2017, Jiangxi Taekwondo won a first prize, two third prizes and one fifth prize.

Team member: Wu Jingyu, born in Jingdezhen, Jiangxi Province. In 2004, she won the first prize of the $49 \mathrm{~kg}$ women's Taekwondo of the World Youth Championship. Two years later, in Doha Asian Games, she won the first gold medal for Chinese Taekwondo. In 2007, she won the first prize of the world championship. In Beijing Olympic Games, she worked hard and won the first prize. Four years later, in London Olympic Games, Wu Jingyu successfully defended the first prize of the $49 \mathrm{~kg}$ women's Taekwondo. [2]

\section{Development Strategy of Taekwondo Team in Jiangxi Province}

The Taekwondo team in Jiangxi Province has cultivated a number of outstanding Taekwondo athletes, it has also won numerous honors for the country and Jiangxi. In recent years, the overall strength has been greatly improved. However, there are still some problems that cannot be ignored. This paper carries out a deeper analysis of the status quo aiming to achieve a corresponding improvement in the strength of the entire team through research.

Strengthen Coaches Team Building. At present, there is only Wang Ting who acts as the coach in Jiangxi Taekwondo team. As a leader of Jiangxi Taekwondo coaches, she is a key force in the development of Taekwondo in Jiangxi Province. However, at the same time, as competitive sports, Taekwondo is bound to be inseparable from the young and energetic coaches. In view of this, Jiangxi Taekwondo coaches staff shortage is extremely serious. In addition, coaches should constantly improve their own level by participating in the various fields of Taekwon do training and learning, study and grasp scientific training methods through modern high-tech means, from psychology, physiology, structure, movement principle and other multi-perspective, while grasp the latest development of Taekwondo, and then better control the training process in every detail, so as to guide the continuous improvement and breakthrough. [3]

Improve the Venue Facilities. Taekwondo sports venues have a certain degree of specificity, in general, standardized Taekwondo venues are covered with Taekwondo mats of the same size according to the size and shape of the venue. Practicing on a good quality mat will not only help improve the technical performance of the athlete, but also avoid the injury of the athlete due to the venue problem. For example: when performing the rotation and take-off action of whirlwind kicking, the force needs to contact with the ground and accomplish by virtue of its own force. If the mat density is low, it is not conducive to the convergence of technical actions, which will affect the training level and physical health of athletes, and have some negative impact on athletes' psychology for a long term.[4] In addition to the basic facilities of the venue, there are also training facilities and ancillary facilities which can also be considered as the necessary material basis for the 
normal teaching of Taekwondo. According to the site investigation of Jiangxi Taekwondo team, the basic facilities are basically complete, such as foot target, sandbags, protective gear, but not particularly perfect, such as tumbler sandbag. The optimization of hardware facilities is an important guarantee for the continuous development of Taekwondo team in Jiangxi Province.

Improve Training. level. Taekwondo is a comprehensive combat program that combines all aspects of athletic performance and body coordination. Technical skills and tactics used in actual combat are the soul of Taekwondo technology. Do not be too ambitious in training. Basic skills such as force, speed, hit effect, accuracy, technical details must be improved.

Strengthen the practice of flexibility. Flexibility refers to the moving extent of each joint of human body and the stretching capacity of muscle and ligaments. It is one of the important qualities of Taekwondo athletes, which has a direct impact on the quality of the completion of Taekwondo movements and mastery of difficult techniques [5]. Taekwondo technical action is mainly done through the legs, so in the training, the flexible requirements are high. People with poor flexibility grasp slower than those with good flexibility. For the people with poor flexibility, some actions are more difficult to accomplish and have some impact on velocity, speed, and height. Taking downward kick of Taekwondo as an example, the goal of this action is mainly the opponent's head and the action essentials are: send the hip and knee to the chest; the leg stretches straightly taking the knee as the axial; the right leg stretches close to the front of the body; the ankle shall be higher than the head. The higher the leg lifts, the more easily to hit the opponent, and the greater the lethality will be. This action fully demonstrates the importance of flexibility. The athlete with poor flexibility will appear stiff in the use of this action and the effect of the action will be significantly reduced.

Improve the overall technology. Taekwondo skills are mainly leg movements and supplemented by hand, and the actual combat is mainly done by legs. There are many kinds of leg methods in Taekwondo. In each method, legs can be low or high, far or near, left or right, extensible or unpredictable, with larger threatening compared with hands.

Increase the difficulty training method. That is to enhance the ability and proficiency of the use of technology by increasing the difficulty of offense and defense training and technical training methods.

Increase the difficulty of technical action. On the basis of being able to skillfully use the technical actions, increase the difficulty and the flexibility, and conduct purposeful training under certain interferences. For example, when holding a foot target to help an athlete practice a horizontal kick, the trainer may randomly move the target with different directions and heights so that the athlete's resilience can be exercised to improve the comprehensive technique level.

Increase offense and defense training. In the practice of a technical action, deliberately increase the difficulty, which can achieve the desired effect faster through practice. For example, during the resistance training, the rubber band can be tied to the designated area of the athlete. During the intensive practice, the athlete can grasp and understand the skill physically and mentally.

Conditional training method. It is designed to train the actual combat of certain technologies and carry out practical exercises under certain conditions so as to achieve the purpose of improving the overall level with the enhancement of local technologies. This training effect will be more targeted, which can obviously change some of the deficiencies in combat, or significantly improve some aspects of the technical level. Therefore, according to the needs of training in peacetime, it is possible to carry out conditional and purposeful exercises in practice to strengthen the skill practiced in a targeted manner. The actual combat training method is a practicing method with practical significance.

Strength training. Taekwondo is a strength-based confrontation project, so in practice, strength exercises are also very important. Since the sport of Taekwondo has developed so far, the style of power confrontation has gradually taken shape. In actual combat, intense antagonism has become its essential feature. In actual combat of Taekwondo, exercise intensity is large with obvious confrontation, which means that athletes have to have a strong strength and plenty of physical fitness, especially the power requirements are more direct. In actual combat of Taekwondo, 
confrontation is mainly done by legs, so the strength and speed of the lower limbs is particularly important. The power of legs is one of the important factors to determine the technical level of Taekwondo athletes. Therefore, the strength of quality is the basis of Taekwondo, but also one of the key exercises in training. [6]

Taekwondo athletes do not only have to strengthen the training of general strength, but also the quality of special forces, so the development of specialized training principles is particularly important. In strength quality training, there must be scientific methods, through scientific exercises to enhance the strength of leg muscles; in strength training for a targeted area, follow the requirements of scientific training, let the muscle group obviously feel resistance.

Cultivate tactical awareness. 1 Develop athlete's tactical awareness. The first step in tactical training which is also a crucial step lays in developing tactical awareness. First of all, athletes should take the initiative to establish tactical awareness in actual combat training, and take the initiative to think and actively choose and apply various tactical suitable solutions. [7] Before each match, athletes shall master the opponents 'tactics, and formulate corresponding tactical solutions. Of course, the coaches' command decisions before the competition cannot be ignored. However, in the ever-changing field of competition, the most important for athletes is still the independent combat and tactical thinking skills and personal on-the-spot tactical adaptability, which only relies on the variety of tactical training experience of athletes. It is also necessary to strengthen the overall abilities of comparison, analysis and judgment of athletes in the actual combat training.

Tactics should not be single, but a variety of mixed uses. In tactical training, athletes shall refine each tactic and cannot use only one tactic, otherwise, the tactic will be known by the opponent. The combination of use of a variety of tactics can greatly improving the use of flexibility. Such training has higher requirements. Athletes do not only have to master the basic tactics, but also to choose the best tactics according to the characteristics of their own and opponents, as well as different situations. At the same time, training should be based on the ability of athletes to adapt to different types of opponents in different situations as soon as possible, and carry out targeted training. Tactical training cannot be too simplified, multi-change tactical combination can increase the chance of winning.

The quality of tactical training shall be put in the first place. Carry out the training of tactical ability, not only to train athletes' abilities of time control and integrated use of tactics, more importantly, to require a high-quality completion of each training, which is the guarantee of the training. Training plan with the term of one week, one month or one quarter can be set up to make the training have a standard, to improve the guiding direction of training.

Tactical training shall be coordinated with a variety of training. Tactical training shall be based on physical, psychological and technical needs, so the tactical training and other training should be coordinated with each other in order to achieve the best training effect.

Strengthen psychological quality training. In training system of Taekwondo, the outstanding athletes pay special attention to psychological training. [8] According to the characteristics of Taekwondo, simulate trainings through various forms of actual combats, for example, opponents simulation, audience simulation training and other links, and multi-scene changes in different exercises. On the one hand, athletes' mental endurance and self-control ability can be improved in such simulated trainings; on the other hand, these simulated trainings also guide athletes to learn some effective self-motivation methods and long-term psychological trainings, which makes athletes be more familiar with the playing field and is easier to make them adapt quickly to the atmosphere to gradually reduce and the phenomenon of exerting exertion. For example, in Taekwondo competition, Player A wants to take a delayed tactical to hold the situation when he gets the higher score. Player B finds the tactic of Player A and then immediately launches a rapid and continuous attack. Then both the two players have the same score, which makes Player A be anxious and panic and ultimately loses the game. From this example, the important status of the psychological quality of athletes in Taekwondo competition can be seen. Only increase the training of psychological quality in normal training to make athletes have a good and stable mentality and good attitude towards the challenges, can athletes have a better level in competition. 


\section{Popularize and Develop Taekwondo in Jiangxi Province and Prepare Taekwondo Talents for Reserve}

To actively bring in Taekwondo classes in school, so that students can understand Taekwondo sports, not only the skills, but also the spirits - modesty and courtesy, earnestly assisting, to make young people practice Taekwondo and love Taekwondo. In addition, Taekwondo association or museum and other ways can be used to further strengthen the training of Taekwondo for young people, to make students have some knowledge of Taekwondo skills, and then to enhance their physical fitness, create a good posture, and promote growth and development; at the same time, Taekwondo can promote physical coordination, flexibility and strength, which is very benef icial to the growth and development of young people; and Taekwondo exercise can enhance the self-protection ability of learners, more importantly, students can be tough, brave and tenacious. [9] The number of amateur or professional teams and learners of Taekwondo is growing, which provides follow-up talents for Taekwondo reserve. Taekwondo athletes in our country are relatively young, and they did not start practicing Taekwondo since they were young. Most athletes are not engaged in Taekwondo exercise for very long time. Of course, it is also related to the late development of Taekwondo in China. However, if athletes' technical movements are not standardized, it is difficult to improve, which results in inadequate development of Taekwondo of China. [10]

To vigorously develop Taekwondo career, Jiangxi Province must promote young people in Taekwondo. Carry out Taekwondo courses in primary and secondary schools, as well as in colleges and universities, and implement the entire training program. The popularization of this sport shall start from children to solve the problem of shortage of athlete source. In addition, focusing on the training of primary and secondary school students in Taekwondo practice, use "combination of physical training and theory training" approach to share system resources, complement each other and strengthen Taekwondo literacy training after school, lay a solid foundation for the training and reserve of talents, promote the popularity and development of Taekwondo, and reserve force for Jiangxi Taekwondo career.

The overall level of Taekwondo in Jiangxi Province is relatively high. It is entirely possible to intensify the efforts of the young people in Taekwondo competitions, popular Taekwondo friendly matches and exhibition games to increase the social influence of Taekwondo exercises. The combination of competitive Taekwondo and public Taekwondo will be synergistic and mutually beneficial while promoting each other. In this way, the implementation of National Fitness Program can be carried out in a down-to-earth manner in order to reserve the follow-up power for the Taekwondo team in Jiangxi Province. The coordinated development of various parties will eventually promote the steady development of the Taekwondo team in Jiangxi Province.

\section{References}

[1] The Current Situation and Countermeasures of Taekwondo in Our Country, [D] Maojun Sun, Weijun Liu. Journal of Capital Institute of Physical Education, 2015-01(In Chinese)

[2] Competitive Taekwondo strength and quality training, [D] Peipei Shang, China Science and Education Innovation Guide, 2012-03(In Chinese)

[3] Taekwondo, [M] Weijun Liu.Beijing Sport University Press, 2013-01 p.12.(In Chinese)

[4] Biomechanical Analysis of Impact of Upper Extremity Movement on Kinematic Structure in Taekwondo Hind Kick Technique, [D]Yujun Tao,Master's Thesis of Northeast Normal University, 2016-05(In Chinese)

[5] To explore ways to improve the quality of Taekwondo teaching, [J] Li Li,contemporary sports science and technology, 2016-10(In Chinese)

[6] Research on the Technical and Tactical Application of Top Female Athletes under Taekwondo Game Rules, [D] Zhang Ting, Mater's Dissertation of Beijing Sport University, 2016-05. (In Chinese) 
[7] Research on Selection of Taekwondo Athletes in Beijing Team Aged between 12 and 15 Years, [J] Zhang Yue ,Master's Dissertation of Capital University, 2014 -05. (In Chinese)

[8] Research on Taekwondo Theory and Practice, Rao Ying [M] Beijing, People's Daily Press, 2017-05. p.117.(In Chinese)

[9] Taekwondo, [M]. Zhen Li Jilin: Jilin Literature and History Publishing House, 2015-08. p.58.(In Chinese)

[10] Research on the Model of Elite Athletes' s Mentality: Taking Taekwondo for Women as an Example, [M]. Dapeng Zhu, Yihai Hu ,Guangdong: Guangdong World Book Publishing Co., Ltd., 2013-12. p.171.(In Chinese) 